\title{
Inhalt
}

STEFAN DEINES, STEPHAN JAEGER, ANSGAR NÚNNING

Subjektivierung von Geschichte(n) - Historisierung von Subjekten.

Ein Spannungsverhältnis im gegenwärtigen Theoriediskurs. 1

I. Subjekt und Geschichte im ,nachmetaphysischen' Zeitalter

HEINZ DiETER KiTTSTEINER

Karl Marx in der Kehre Heideggers .25

THOMAS R. WOLF

Leben in Geschichte(n). Zur Hermeneutik des historisch-narrativen Subjekts ...47

STEFAN DEINES

Über die Grenzen des Verfügbaren. Zu den Bedingungen und Möglichkeiten kritischer Handlungsfähigkeit.

HANS-HERBERT KÖGLER

Situierte Autonomie. Zur Wiederkehr des Subjekts nach Foucault

MORITZ BAßLER

Das Subjekt als Abkürzung.

ELIZABETH DEEDS ERMARTH

The Trouble With History.

\section{Theorie und Geschichtsschreibung}

STEPHAN JAEGER

Geschichte als Wahrnehmungsprozess. Ihr selbstreflexiver Vollzug in der Geschichtsschreibung.

MARIAN FÜSSEL

Die Rückkehr des, Subjekts' in der Kulturgeschichte. Beobachtungen aus praxeologischer Perspektive 


\section{Helmut Galle}

Das Subjekt angesichts des Äußersten. Zeugnisse von Holocaust-Opfern als

Dokumente für die Widerständigkeit von Subjektivität

DANIEL FULDA

Hat Geschichte ein Geschlecht? Gegenderte Autorschaft im historischen

Diskurs

III. Inszenierungen von Subjekt und Geschichte in Kunst und Literatur

\section{STEPHEN BANN}

Oscillations of the I. Academic Painting after the French Revolution (Louis Hersent, Léopold Robert, Paul Delaroche)

DOROTHEE KIMMICH

Charlie Chaplin und Siegfried Kracauer. Bemerkungen zum Verhältnis von

Geschichte, Kunst und Kino

ANSGAR NÜNNING

Die Rückkehr des sinnstiftenden Subjekts. Selbstreflexive Inszenierungen von historisierten Subjekten und subjektivierten Geschichten in britischen und postkolonialen historischen Romanen der Gegenwart.

SABINE KYORA

Literarische Inszenierungen von Subjekt und Geschichte in den Zeiten der

Postmoderne

\section{SILKE HORSTKOTTE}

Literarische Subjektivität und die Figur des Transgenerationellen in Marcel Beyers Spione und Rachel Seifferts The Dark Room.

MARCEL BEYER

Das wilde Tier im Kopf des Historikers

$\mathrm{Zu}$ den Autorinnen und Autoren 303

Index 